\title{
The Impact of Fan Cultures on Teenagers Consumption Value
}

\author{
Bixuan Chen ${ }^{1, \dagger}$, Yuhong Feng ${ }^{2, *}, \dagger$, Rongfei Sheng ${ }^{3, \dagger}$ \\ ${ }^{1}$ International Division, Suzhou International Academy BFSU, Suzhou, Jiangsu, China \\ ${ }^{2}$ Brookes Westshore, Victoria, British Columbia, V9B1W2, Canada \\ ${ }^{3}$ Maranatha High School, Pasadena, Los Angeles, 91105, United States \\ *Corresponding author. Email: sheng.fay@maranathastudents.org \\ Those authors contributed equally.
}

\begin{abstract}
Consumption concept is the guiding ideology and attitude of human beings towards their disposable income, and teenagers will be affected by various things before this concept is fully formed. Thereinto, fan culture, as one of the mainstream cultures of contemporary teenagers, will have a huge impact on teenagers' consumption concept. These new items have greatly impact on the consuming behaviour of teenagers, i.e., teenagers are easily affected by idols and celebrities. This paper will study the specific phenomenon and causes of the influence of fan culture on the consumption values of teenagers. Through self-made questionnaires and some literatures, it is concluded that this phenomenon can be attributed to the cognitive and psychological needs of teenagers at a specific stage. Secondly, teenagers should have a correct view of consumption, rather than blindly impulsive consumption. At the same time, the paper points out how to improve the negative impact of this phenomenon in the future. These results reveal that the negative influence of fan culture on teenagers is very serious.
\end{abstract}

Keywords: Teenager, Subculture, Fan culture, Expense value

\section{INTRODUCTION}

With the rapid development of social media in the society today, celebrity fans gradually formed organizations, forming China' $s$ fan culture. Fan culture, as a specific feature of subculture, is not in line with the conventions. People began to consciously construct their identities through their own choices and values. Among them, consumption is an important aspect. In this society, fan culture is dominated by media discourse, where celebrities occupy mass media coverage and attract fans.

On September 4, 2021, China's "Observer" posted this news: "Chinese fans customize "exclusive plane" for Korean group member Park Ji Min, raising more than 2.3 million yuan in one hour ".[8] What's even more outrageous is that three minutes after the release of the crowdfunding, the total amount reached over 1 million yuan. Some netizens said they couldn't understand this kind of support, believing that some of the fans who participated in the fund raising were not financially independent and most of them were teenage groups, and this kind of support should not be promoted.

In such an era, it is necessary to investigate the fan culture impact on the youth's self-construction and identification, the way these methods of selfconstruction a result from the consumption values of teenagers as well as the inevitable connections between them. This assay will analyse these aspects to find the internal roots of the fandom phenomenon. Though out the assay, the result is expected to show the impact of fan cultures has mostly negative impact on teenagers' consumption value.

\section{THE DEVELOPMENT HISTORY OF SUBCULTURE AND ITS INFLUENCE ON CHINA}

\subsection{The history of subculture}

Subculture, also known as non-mainstream culture, refers to a specific group whose cultural form, content and value shows some degree of variation from the 
mainstream cultural background. The concept of subculture began in the early Western countries and was first proposed in 1886. Its development and emergence have gone through the Chicago School and the Birmingham School in two periods. The research content of the Chicago School includes study of ethnic immigration, criminal behavior, gender. It focuses on the culture of a group that is different from the larger group to which it belongs. Early studies of the Chicago School provided explanations and solutions to societal problems in the U.S at that time. Starting in 1964, the Birmingham School began to rise under the impact of World War II. It faced many social welfare issues and cultural shock issues. The Birmingham School period was the heyday of subculture development, but it gradually declined as time passed on. In July 2002, following the closure of CCCS(center for contemporary cultural studies) by the University of Birmingham examiner, the study of subculture came to a phased end.[5] As a result, post-subculture era began, and the main research subject became the phenomenon of the youth a closure of CCCS(center for contemporary cultural studies) by the University of Birmingham examiner, the study of subculture came to athey are gradually recognized. When the youth subculture gradually became popular in China, a new pronoun appeared, fan culture. It is difficult to have an accurate definition of fan culture because it is still evolving. Generally speaking, fan culture is the term for individuals and groups that fulfill their psychological needs by participating in fandoms and group labels around idols through collective, organized communications.

\subsection{The development of fan culture in China}

Chinavelopment of fan culture inrough three stages. First, it consists of an audience formed by the one-way dissemination of media. Then, fans evolve as consumers under the influence of market changes. Lastly, fans become more interactive as radical changes in the media occurred. In the early 1980s, the domestic market began to form. At that time, because of the one-way nature of the dissemination of popular culture, fans could only passively accept messages from idols, and their actions are limited to only follow idolsa occurred. In the hat fans could do was putting up posters on the wall and share the idols the one-way nature of the dissemination of popular culture, fans could only passively accept messages from idols, and their actions are limited to only follow idolsa occurred. In the d. Color TV was gradually installed in majority of households. Many first-generation talent show, e.g., the Super Girls, entered peopleoplerity of households. Many firstgeneration talent show, e.g., the Super Girls, entered peoplens could only passively afirst time that Chinals, entered peopleoplerity of households. Many firstgeneration talent show, e.g., the Super Girls, entered peoplens could only passively accept messages from idols, and their actions are limited to only follow idolsa occurred. In the brought from fanhinals, entered peopleoplerity of households. Many first-generation talent show, e.g

\subsection{The influence of fan culture to the teenagers}

With the rapid development of the Internet, social media gradually took shape, and the role of fans were extended. Fans began to use social media to systematize fan culture. Fans can participate in idol activities in an organized and large-scale manner, such as online voting, giving better ranks to idolons are limited to only follow idolsa occurred. In the promoting idolss began to use social media to systematize fan culture. Fans can participate in idol activities in an organized and large-scale manner, such as online voting, giving better ranks to idolons are limited to only follow idolsa occurred. In the $s$ in modern society, fans are increasingly willing and capable to spend more money for their idols. According to a survey found on the website of the China National Forum, $42.2 \%$ of middle school students started to become fans in elementary school, and $52 \%$ of middle school students were fans for more than 3 years, which means that the average age of fans is gradually declining.[4] The profits brought by fan culture to the economy have increased year by year. China, as a consumer-oriented society, begun to exploit the commercial value of idols. Consequently, fans are paying more financial and personal efforts for their idols. Capital began to increase the commercial opportunities of idols. In order to support idols, fans had to spend high prices to buy the same products used or promoted by idols, and many celebrities began to create their own brands. Nowadays, the average age of fandoms is declining, where lots of fans are still teenagers. On this basis, most fans do not have the ability to be financially independent, and they can only spend their parents celebrities began to create their own brands. Nowadays, the average age of fandoms is declining, where lots of fans are still teenagers. On this basis, most fans do not have the ability to be financially in and they have no awareness about the amount of money they have spent. Contemporary fan culture has become a huge brainwashing show, and those so-called lots of fans are still teenagers. On this basis, most fans do not have the ability to be financially inhem, i.e., they spend more money and time for idols. For example, this is seen in the fandoms from Chiname a huge brainwashing show, and those so-called lots of fans are still teenagers. On this basis, most fans do not have the ability to be financially ine more money you spend, the more votes you can cast. If you can't pay for seen in the fandoms from Chiname a huge brainwashing show, and those socalled lots of fans are still teenagers. On this basis, most fans do not have the ability to be financially in hashtags. 
Younger fans are extremely vulnerable to these remarks and will become wallets and workers for the capital.

\section{ANALYSIS OF THE PHENOMENON AND PATTERNS OF FAN CULTURE THAT INFLUENCES THE CONSUMPTION VALUES OF TEENAGERS}

\subsection{Identity}

In essence, self-identification is a kind of cultural or value belonging, and teenagers are in a critical period of self-positioning, which makes this period chaotic. In his published youth cultural motif and its contemporary representations, Ban Jianwu mentioned that "Because of the influence of their social role positioning, teens will inevitably be subject to various regulations and restrictions from adult society. Those have aroused their sense of rebellion so that teens can express themselves in various ways and create a kind of cultural and value legitimacy for their social existence". In this stage, the benchmark external objects of adolescents' behavior generally affect their social value identification through the surrounding environment. In the current mediaoriented postmodern consumer era, young people will habitually base their benchmarks on those they think are worthy of being called idols and influence their behavior and judgment. The target of fan culture is the stars who represent the excellent values in the hearts of their fans; not only do they have a profound influence on the identity and value orientation of teens, but also the consumption values of young people. In this article, the focus of fans' pursuit of idols is limited to the subjects they love, that is, their favorite stars.

\subsection{The status quo of Chinese idols today}

In today's Chinese society, celebrities with huge followings have become the only criterion for testing idols. Famous stars do not rely on excellent acting skills or well-known movies but on the capital boost and a strong marketing organization which causes fans to form an illusion. A passage from Nanmei internet about "how people today have seen famous stars?" shows that "80\%-90\% of non-fan groups tend to use free services, and only 10\%-20\% are willing to pay. Fans are willing to pay as high as $60 \%-70 \%$ because of their admiration for traffic stars"[3]. Therefore, the relationship between contemporary idols and fans is mutually beneficial. Idols gain fame through the consumption of fans, and fans can get closer contact with idols. The consumption relationship between idols and fans can directly affect the consumer behavior and consumption concept of teenagers. We can look at this problem through two patterns.

\subsection{Consumption pattern-direct}

The first pattern is to guide teens to spend on specific idols directly. Through the fan club, fans "manage fans, promote idols, and connect with major media activities and companies." The management of the fan club also includes many offline activities, such as cheering, fundraising, offline advertising. Fans raise funds to help their idols grow fame so that they can receive more endorsements and resources. However, some fans have done a lot of irrational behaviors. For example, the model "Hongqiao First Sister" worked tirelessly in the star chasing session and often stayed at Hongqiao Airport to get autographed photos and group photos of many celebrities. however for these reasons, she gave up her studies and her everyday life, and now she can only live to depend on her part-time job. Moreover, another irrational example is Yang Lijuan, the originator of star chasers, who dropped out of school at the age of 16 and even sold her family property to obtain the opportunity to meet Andy Lau. To help Lijuan realize her dream, her father sells her kidneys, and unfortunately, chooses to commit suicide by jumping into the sea. By chasing stars, they have neither fulfilled their dreams nor have they lived a good life. Some teenagers spend most of their living expenses or pocket money on new albums released by idols and concert tickets. Due to the recent influx of celebrities, tickets to see them have become more difficult to obtain, and the price is severely premium. Young fans borrow money everywhere, work illegally to make money, and even save money to accomplish their desire to meet idols. These consumption are irrational. Of course, moderate fan culture is more conducive to young people. Reasonable fans will buy some posters and peripherals of idols, which are daily necessities needed with photos or autographs of celebrities loved by young people. They use these peripherals and posters to inspire their study and life and make themselves feel connected to the idols young fans pursue. The questionnaire from the writers of this paper shows that "80\% of teenagers reward their performance by buying peripherals or putting posters in the room, and $75 \%$ of teenagers will make themselves feel better because they see their idols' posters every day." These entertainment expenses above the regular consumption are endowed with value and emotional meaning to a greater extent. Rather than saying those are posters, there is more about the propaganda of values and the radiation of young fans' desire for idols.

\subsection{Consumption pattern-indirect}

The second pattern is to guide teens' consumption indirectly. Since teenagers are inherently susceptible to the influence of the environment, they are more likely to be affected by the behavior of their star-chasing friends. Many teenagers choose to buy expensive clothes or 
jewelry that they do not need or cannot afford to not feel inferior in interpersonal relationships. Therefore, these expenses in the consumption conditions alleviate teenagers' comparison psychology and inferiority anxiety. Some fans are envious since they see other fans' videos of idols being close to those fans, so they start borrowing money from their parents or fulfilling their wishes through other unlawful means. These types of consumer behaviors are irrational and have a significant impact on young fans' values. However, most celebrities will encourage fans not to spend money for themselves, but to spend it properly. Spend more time with family, travel around the world, or buy more things needed in life, instead of fantasizing and consuming emotional value to unrelated people. For example, the famous Chinese singer Jay Chou made a song called "Listen to Mother's Words" to tell fans that family is the most central part of life, rather than spending money for idols aimlessly. Most celebrities also send Weibo through special holidays, such as Mid-Autumn Festival, National Day, and The Chinese New Year, influencing young fans to spend more time with their families during these festivals. They use their behavior as the model to let fans experience the correct consumer values. The pattern of indirect expense effects has both disadvantages and advantages. Regardless of whether it is indirect or direct, we can recognize the influence of fan culture on teenagers' consumption values and the specific effect through the above two patterns. Of course, in addition to irrational star-chasing behavior, a moderate fan culture can also effectively help young fans improve their lives.

\section{THE SPECIFIC REASONS AND SOLUTIONS OF THE INFLUENCE ON TEENAGERS' CONSUMPTION VALUES}

\subsection{Teenagers' expense habits}

For teenagers, they are in a period of need to be guided. Their values were not completely perfect, especially the expense value. They come into contact with any new things have positive or negative effects on their values. This period of teenagers will be looking for a brand of idols, some people they will make track for a star, put on the market of the idol as their example, popular and make track for a star has become a social youth groups in the mainstream values and a kind of behavior patterns. The impact of star-chasing on their consumption values is particularly prominent. The behaviors of idols in society can have a huge impact on teenagers. For example, the consumption power of stars is different from everyone's situation. They are a transitional consumer group, which can be fully reflected in their unique values, behaviors and consumption habits. When they have money in their pockets, they will buy the goods they like as much as they want. When they are shopping, their willpower is poor, they do not need to consider other things, because they have not achieved economic independence, their parents will still be their source of income and give them economic support.[9]

\subsection{Reasons for consumptions for their idols}

"Star effect" will make the youth to follow their idols, when idol bought a piece of goods, fans will want to buy icon with money, but most idols are adults, and have their own income, have developed into a correct consumption and values, and teenage fans haven't can achieve economic independent ability. They use the money they get from their parents to buy the idols' peripheral or similar style, concert tickets, celebrity endorsement. Some of them will blindly use a large amount of their living expenses to buy a large number of idols, and they will attach their love for idols to any products related to idols. If their idols endorse products, they will buy them crazily, thinking that this is also a kind of support for their idols. There are also some extreme fans who will stop buying a brand if a celebrity they don't like is endorsing it. Teenagers have some misunderstandings about consumption. Many people think that more pocket money means more spending power for teenagers, but this is not the case. Consumption power refers to the ability to buy and pay for the required consumer goods. More money on hand, can only indicate that there is a certain monetary ability to pay. Improving consumption power is more about improving the ability to buy, which also depends on the knowledge and experience acquired by teenagers. Hence, they can buy the most satisfactory and satisfying goods that best meet their needs with the same amount of money. So far, the biggest characteristics of teenagers' consumption is that the consumption concept is open, the consumption mode is diverse, the consumption level is improved, and the proportion of satisfying personal development and spiritual enjoyment is gradually increasing. The body and mind of teenagers are in a period of rapid change and rapid development, and there is a large consumption demand. On the one hand, a large number of material products need to be consumed to meet the needs of physical development. On the other hand, teenagers have a transformational thirst for knowledge and a very strong sense of novelty and curiosity in the external world, which requires consumption of spiritual products to satisfy their thirst for knowledge. [10]

\subsection{The solution of establishing their expense value}

However, teenagers lack relatively stable ability of commodity identification, selection ability, evaluation ability and purchase decision, and consumption is easily affected by emotion, often appear to buy on whim, after paying the money regret. Parents and schools should 
help teenagers form a correct consumption value, which is very important for the healthy growth of teenagers and the development and progress of society. It is difficult for teenagers to avoid these problems on their own. They basically cannot restrain themselves and learn correct consumption values by themselves. Therefore, we need schools, society and parents to help teenagers form correct consumption values. Schools and families can work together to make some rules and regulations to help teenagers regulate their consumption. In society, it takes people on the Internet, or even the state, to strictly regulate behavior.

\subsection{Measures taken so far}

In August of 2021, an account on the China Central Website posted a message that weibo would eliminate the function of super topics and products that guide fans to consume extra money. It set an example for teenagers in terms of consumption behavior. We should continue to intensify efforts to urge online platforms to regulate consumption and guide fans to rationally pursue idols. We would like to see more measures implemented in favor of the expense values of teenagers.

\section{CONCLUSION}

In summary, we investigate the impacts of fan culture on teenagers expense value and find two rules for this phenomenon. One is that adolescents' irrational and immature thoughts lead them to convert their fanatical love for their idols into money to get close to their idols. Another is the psychological comparison among teenagers, which results in larger cost on products related to their idols compared with other fans. Fan culture can profoundly affect the values of some teenagers, partly because of their irrational thinking. We hope that in the future, teenagers' consumption values can be regulated more systematically after being influenced and guided by society and family. Apparently, they can improve their consumption concepts through the consumption process in a more logical way. These results offer a guideline for further study of the influence of fan culture to adolescents comsumption value.

\section{REFERENCES}

[1] Ban Jianwu. (2011). Identity: Adolescent Culture Motif and Its Contemporary Representation. Educational Science, 5, 79-85.

[2] Xu Yilin. (2019). Research on the Status Quo and Guidance of Fan Consumption Behavior of Contemporary College Students (Master's thesis, Chengdu University of Technology).

[3] What do you think of traffic stars in today's society? https://m.nanmeitrip.com
[4] Monthly magazine, A survey on teenagers' star worship: Vigilance against the erosion of mainstream values by fandom thinking, 2020, June26 http://www.xinhuanet.com/202006/29/c_1126170695.htm

[5] Ruiling,Huang. "The development of subculture from Chicago School to Birmingham School" Foreign theoretical trends,vol.11, 2007, pp.77-81

[6] Dengying, Meng. "A brief analysis of the formation history of the concept of subculture." Foreign Literature,vol.6,2008,pp.93-102

[7] A Brief analysis of the formation history of the concept of "subculture". (n.d.). https://www.ixueshu.com/document/40f861bf97f9f 06f.html.

[8] 60 minutes to raise 2.3 million, Chinese fan support group customize plane for Korean artist_朴 智旻 . _ Park Ji Min. (2021, September 5). Retrieved September 28, 2021, https://www.sohu.com/a/487937074_118927.

[9] On the establishment of teenagers' correct consumption concept http://www.lunwenstudy.com/shehuirl/156751.htm 1

[10] The influence of celebrity endorsement on teenagers' consumption concept https://wenku.baidu.com/view/39edba513c1ec5da5 0e270ea.html 